\title{
Delta Studies: 7 Propositions for Arts/Sciences Education
}

\author{
Robin van den Akker ${ }^{1 *}$, Liesbeth Noordegraaf-Eelens ${ }^{2}$, Bregje F. van Eekelen ${ }^{3}$, Roger Teeuwen 4 \\ 1 Erasmus University College, Erasmus School of Social and Behavioral Sciences, Erasmus University Rotterdam, \\ NETHERLANDS \\ ${ }^{2}$ Erasmus School of Philosophy, Erasmus University Rotterdam and Codarts University for the Arts, NETHERLANDS \\ ${ }^{3}$ Faculty of Industrial Design Engineering, Delft Technical University, NETHERLANDS \\ ${ }^{4}$ Willem de Kooning Academy, Hogeschool Rotterdam, NETHERLANDS
}

*Corresponding Author: vandenakker@euc.eur.nl

Citation: van den Akker, R., Noordegraaf-Eelens, L., van Eekelen, B. F. and Teeuwen, R. (2021). Delta Studies: 7 Propositions for Arts/Sciences Education. European Journal of STEM Education, 6(1), 18. https://doi.org/10.20897/ejsteme/11394

Published: December 2, 2021

\begin{abstract}
Living in a Delta, amidst water, land and air, means living and engaging with complex concerns. To address these concerns the Rotterdam Arts and Sciences Lab (RASL) has developed an education- and research program for Higher Education in which the (alpha-, beta-, and gamma-) sciences and the arts are combined to engage with with all of the scales, entanglements and complex societal concerns of this Delta-multiple: Delta Studies. Delta Studies can therefore be understood as a companion to the alpha, beta and gamma sciences, as it sets out from and blurs, 'composes' (Latour, 2010) and 'composts' (Haraway, 2016) with, the sciences and the arts. Delta Studies exists through combining and composing with the skills and knowledges of the arts and the sciences as well as the situated knowledges of societal partners. In this manner, it questions existing hierarchies of ways of knowing and making public(s) in order to create new ways to engage with complex concerns and reimagine our collective futures. This article presents the guiding propositions of Delta Studies.
\end{abstract}

Keywords: Delta Studies, Rotterdam Arts and Sciences Lab, Arts and Sciences Education

'What if we could hear the Higgs boson?'

Eldred, S. (2016). Art-Science Collaborations: Change of perspective. Nature, 537, 125-126.

\section{INTRODUCTION: WHAT IF}

Living in a Delta, amidst water, land and air, means living and engaging with complex concerns. It means cohabiting with humans, animals, objects, technologies, and infrastructures as well as with their collective histories and, especially, their entangled futures.

On the occasion of the 100th question asked to the Dutch Climate Helpdesk, which is staffed by a group of scientists and answers questions from the general public, one of its initiators, an oceanographer, was invited on national radio. This milestone had been reached in under three months and he illustrated the wide variety of questions he and his colleagues responded to in this period, relating to anything from solar panels and e-bikes to plastic soup and global warming. The relatively high demand for such a thing as the Climate Helpdesk illustrates 
both the widely shared need to act in response to what is often labelled as the Climate Crisis and the multiple scales, levels and entanglements that constitute the very situation in which we need to respond - that is: be able to respond, be response-able (see Haraway, 1992, 1997, 2016; Despret, 2004, 2016; and Barad, 2007).

Yet our oceanographer-perhaps unwittingly—also illustrated that, while scientific knowledge is a necessary component of being response-able, in itself it is not and cannot be sufficient to imagine modes of existence that enable living and engaging with complex concerns, their collective histories and their entangled futures. Reflecting on a question about the plastic soup in our oceans, which spoke to his own discipline, he gave an academically sound lecture. He connected the plastic in our oceans to the plastic in our backyards, to the fossil fuels that go into producing plastic, to burning fossil fuels in general, to rising CO2 levels, to global warming, to rising sea levels, etc.

What is response-ablity in the face of such a complex societal concern? Where and when is a response enabled? What would be its scope? At a loss, and with a sigh of resignation, our oceanographer asked: 'What if... what if we could see $\mathrm{CO} 2$ as a purple cloud? Perhaps we would do more...'

The Rotterdam Arts and Sciences Lab, a collaboration of Erasmus University Rotterdam, Codarts Rotterdam and the Willem de Kooning Academy/Hogeschool Rotterdam, argues that it is precisely the 'What if...'-questions that can help us overcome the very same resignation experienced by our Oceanographer. For 'What if' is the first proposition of all possible worlds; it is the question that enables a re-imagining of the present and alternative ways of doing, thinking, and making with and beyond the disciplinary practices of the sciences and the arts. In the Dutch language we speak of the alpha-, beta-, and gamma sciences. Over the past few years the Rotterdam Arts and Sciences Lab (RASL) has developed an education- and research program for Higher Education in which the (alpha-, beta-, and gamma-) sciences and the arts are combined to engage with the Delta multiple, with all of its scales, entanglements and complex societal concerns: Delta Studies. Delta Studies can therefore be understood as a companion to the alpha, beta and gamma sciences, as it sets out from and blurs, 'composes' (Latour, 2010) and 'composts' (Haraway, 2016) with, the sciences and the arts. For us, Delta Studies exists through combining and composing with the skills and knowledges of the arts and the sciences as well as the situated knowledges of societal partners. In this manner, it questions existing hierarchies of ways of knowing and making public(s) in order to create new ways to engage with complex concerns and reimagine our collective futures.

We outline seven propositions for Delta Studies, i.e., an approach towards education (and research) with the sciences and the arts developed in the context of the Rotterdam Arts and Sciences Lab. This approach has emerged from our dual degree programme in which students obtain a degree from an arts institution (the performance arts at Codarts or the visual arts at $\mathrm{WdKA}$ ) and can graduate in a wide variety of academic disciplines at Erasmus University Rotterdam (Arts and Culture Studies and the Humanities, Social and Behavioral Sciences and Economics and Busines, as well as Life Sciences). Whereas students follow parallel tracks in the dual degree programme, we developed, too, the Minor Re-Imagining Tomorrow through the Arts and Sciences (30 EC) (De Groot, 2020) and various extra-curricular Studios in which students and particpants with disciplinary backgrounds in the arts and/or sciences can collaborate and compose together with societal partners in order to engage with complex societal concerns. The Minor was recently awarded the first Dutch Education Premium (Nederlandse Onderwijspremie') by the Dutch Ministry of Education. ${ }^{1}$ Currently, we are designing a transdisciplinary Bachelorand Master Programme and setting up a transdisciplinary research programme. Rooted in Science and Technology Studies and New Materialist thought, these seven propositions are our points of departure when it comes to doing education and research with, and beyond, the arts and sciences.

\section{DELTA STUDIES IS SITUATED AS A DELTA}

A delta is as much comprised of land, water, and air as it consists of the entanglements between human and non-human creatures, subjects and objects, techniques and technologies, infrastructures and circulations across various scales. Delta is scale; and like all scales, the Delta is imagined and requires (imaginative) work (Tsing, 2000). Therefore, scaling the delta is a verb. The delta does not stop at man-made boundaries (nation-states, provinces, water/land distinctions). Delta Studies incorporates their making and their effects in its enquiries. The Mannheim convention (1858) for instance enables the life, traffic and trade along the Rhine. In Delta Studies, the boundaries between water, land, and air dissolve. The delta is a delta because of its entangled becomings.

Methodologically, we approach the delta intentionally as localized and local—it is comprised of cables, electricity, fishery, windmills, roads, waterways, neighborhoods and social institutions. But "local" means it is also always already tied up with hinterlands and with specific international flows, such as outsourced labor and containers that come and go (and some that stay as student housing). Delta Studies also connects to other deltas, and actively fosters exchanges with other delta areas.

1 https://www.rijksoverheid.nl/actueel/nieuws/2021/01/14/eerste-nederlandse-hogeronderwijspremie-voor-zes-onderwijsteams. 
Time-wise, Delta Studies takes a long view. A delta concern cannot be solved in 100 days (a design challenge) or 2-4 years (a standard period for research projects). Delta Studies dares us to ask for longitudinal studies that don't follow education and funding rhythms. A delta concern, moreover, has its own rhythms, and these rhythms are part of what needs to be investigated. Living in a delta means cohabiting with humans, animals, objects, technologies, and infrastructures, each with its own (known and unknown) histories and possible futures. Since we are in it for the long run, Delta Studies engages and seeks to create room for the unknown, disturbances, indeterminacies, failures, and changing visions. Multiple futures are in fact made and imagined in the Delta. Delta Studies examines what histories of the future the Delta has already metabolized (e.g., Maasvlaktes, Rhine futures), while defuturing (taking away futures of humans and non-humans) takes place on a large scale.

The Delta may be thought of as layered (loosely following the Annales school), but we don't work in the layers but through the layers. We look for instance at how infrastructures change culture, and how culture reworks infrastructures. Deltas are sustained by multiple entanglements and enfold many circulations across scales - from the local to the planetary. Deltas are always already multiple.

\section{DELTA STUDIES ENGAGES WITH COMPLEX CONCERNS}

The Delta is a living system. Students and researchers can learn to design with the tide while engaging with complex societal concerns. Complex societal concerns are not problems to be solved, fixed or tackled in the short term. They are are societal issues that impact us (in the broadest possible sense), while bringing together humanand non-human creatures, living things and '(hyper-)objects', like class or climate (Morton, 2013), in an entangled, multi-layered manner and across times, spaces and scales. Such concerns are too complicated to handle as a problem and to be 'tackled' with solutionism - so, instead, we engage ourselves with it, by e.g., working on fostering long-term coalitions. In this manner, Delta Studies moves back and forth between 'matters of fact' (decontextualized scientific findings) and 'matters of concern' (the complex networks that make and sustain something or someone in its particular situatedness) (Latour, 2004; but see also Barad, 2007, 2010, 2015; Haraway 1992, 1997, 2016; Blaise et al., 2017). This is not to say 'everything [is] connected, without adequately addressing the complex structure of connectivity' (de Frietas, 2016, p.2, as cited in Blaise et al., 2017). The Delta Studies approach takes the ontological irreduceability of a complex concern as a starting point, yet demands epistemological reduction, while mapping the relations, connections, links, threads, ties, etc. of a specific issue (see also Latour, 1993, p.158). 'Why? Because to explain is to reduce' (Bryant, 2013).

While mapping the concern, we assemble coalitions with relevant knowledge, imagination, expertise, and skills. We ask ourselves, for which lines of inquiry do we need others? And, how can we reciprocally be of benefit to one another? The goal is not to create scalable one-size-fits all solutions. Some concerns need to be on the agenda for a longer period than design challenges or research grants allow for. Some concerns are too complicated to handle as a problem and be 'tackled' with solutionism - so, instead, we engage ourselves with it, by e.g., working on fostering long-term coalitions. Delta Studies makes students - artists, scientists - astute problem (re-)framers, and capable of identifying and exploring different presents and alternative futures with and through situation-specific compositions.

\section{DELTA STUDIES IS PREMISED ON EQUALITY OF KNOWLEDGES}

The premise of Delta Studies is that compositions of artists, scientists, and societal actors can only work when the composing itself takes place without hierarchies across its components. It is important to avoid that one discipline orders or structures the other components and therefore reduces a priori the complexity and outcome of the composition. To engage with complex societal concerns we need a multisensory approach and an equality of knowledges.

This equality of knowledges is an ongoing practice, something to strife for, and most surely not a given. It needs constant work and reflection, and hence adaptation. In her outline of the 'provisional pedagogies' that inform the education in the RASL Minor Re-Imagining Tomorrow through the Arts and Sciences, Tamara de Groot (2020) writes (and its worth citing her at length):

To enable this, we make explicit and work with the frictions, conflicts and paradoxes inherent to transdisciplinary practice across and beyond the arts and sciences. These tensions emerge as a result from the coming together of people with different disciplinary backgrounds, world views, ways of knowing, dispositions and practices. In so doing we aim not to gloss over such differences and tensions, but to make them productive. While there are differences between participating members in any collaborative setting, in transdisciplinary collaborations the acknowledgement of, and working with 
difference is essential because it makes visible disciplinary logics and paradigms. Difference in transdisciplinary collaboration manifests itself in zones of tension, where discipline-informed ways of doing clash with each other and with certain core aspects of transdisciplinary practice.

These 'zones of tension', she argues, arise not simply from collaborating between and across different disciplines. They arise because, in a situation where the equality of knowledges is presumed, teachers and students (1) are "challenged to not only "bring in" knowledges and practices, but to critically reflect on the knowledges and practices they are already working in (and which they might not be very aware of)' and (2) they need to cultivate an 'attitude of attention and curiosity with regards to other ways of knowing and acting' (De Groot, 2020).

\section{DELTA STUDIES REIMAGINES TOMORROW THROUGH COMPOSITIONS}

Engaging with complex concerns requires situation-specific compositions of, and composing with, artists, scientists, and societal partners. Arts, sciences, society. Each territory comes with its own form of knowledge production (epistemologies), way of speaking (languages), and modes of making publics (valorisation). Each territory comes, in sum, with its own dominant logics. Such logics are not encompassing all practices in these territories, but rather are the dominant modes of engaging with the world. Within its zones of tension, RASL brings together these three logics; three logics that each are necessary to formulate a response to complex concerns, but that—each on their own, individually—are not sufficiently able to do so:

- The 'what is'-logic of the sciences through which objective truth claims are constructed and facts are assembled (Latour and Woolgar, 1986);

- The 'as if -logic of the arts, and especially contemporary arts (Vermeulen and Van den Akker, 2010, 2015), through which speculative embodied knowledges, involving all the senses, are developed;

- The 'if, then'-logic of current risk societies (Beck, 1992), in which future risks are managed through protocols, scenarios, algorithms, war games, and dilemmas: IF [Event], THEN [Consequences].

By bringing the distinctive logics of these realms together in a composition of equals, we can mobilise transdisciplinary ways of doing and thinking (while preventing evermore disciplinary ways of acting in, and seeing, the world). For we contend that it is only through composing with scientific-, artistic- and situated (of societal partners and students with diverse backgrounds) societal knowledges, imaginations, skills, and expertise that we can enable transformative response-ability, enable $\Delta$. Delta Studies bring together these three different ways of thinking and doing, making, creating, performing, seeing and feeling, unpacking and interpreting, speculating and representing so as to be able to pose "What if"-questions. Such questions re-imagine the present in order to make public(s) for future modes of being, for alternative tomorrows.

\section{DELTA STUDIES AIMS FOR TRANSFORMATIVE RESPONSE-ABILITY}

Delta Studies makes explicit and works with and through the frictions, conflicts and paradoxes inherent to (transdisciplinary) practices across and beyond the arts and sciences. Tensions emerge as a result of the coming together of different disciplinary paradigms, world views, ways of knowing, dispositions and practices. Yet Delta Studies does not gloss over these zones of tensions. It 'stays with the trouble' (Haraway, 2016). It responds to them by making them productive in the process of becoming response-able- - that is: discovering what it is that one can and cannot contribute while composing for societal transformation (Haraway, 1992, 1997, 2016; Despret, 2004, 2016; Barad, 2007)

In their insightful article 'Towards a Response-able Pedagogy Across Higher Education Institutions in PostApartheid South Africa: An Ethico-Political Analysis’, Bozalek and Zembylas (2017) rightly argue:

Response-able pedagogies are also ethico-political practices which incorporate a relational ontology into teaching and learning activities and thus extend their transformative potential. In other words, responseable pedagogies constitute relational processes through which social, political, and material entanglements in higher education (i.e., students, facilitators, discourses, texts, performances, drawings, face-to-face and online comings-together) are rendered capable through each other to bring about social transformation. [...] The turn to matter within new materialist thought foregrounds the productive qualities of the co-implication of bodies, power, ethics and subjectivities within pedagogical processes. Bodies, power and subjectivities, of course, have been explored previously in education research (e.g., see Youdell 2006), however, the conceptual shift of new materialism that is pedagogically significant is the incorporation of a relational ontology where bodies and matter are entangled and are endowed with 
agency and complexity and resist being posited as inferior to language or discourse (Hickey-Moody, Palmer and Sayers 2016).

In Delta Studies, transdisciplinary compositions (i.e., 'entanglements of bodies and matter') collaboratively compose for social transformation. This implies agency. The key questions, however, which one is forced to answer when living and working in deltas, always pertain to scale and scope. This requires constant reflexivity, constant scaling and scoping: Where do we compose? And with whom and for whom? Do we do difference? Do we make difference? Do we add matter? Do we matter?

\section{DELTA STUDIES DOES NOT MAKE A DIVISION BETWEEN EDUCATION AND RESEARCH}

Delta Studies does not separate learning from knowing; education is research and research is education. Academics, artists, students and staff involved in Delta Studies act as researchers together, compose together.

In this context, 'staying with the trouble' (Haraway, 2016) also requires a focus, and reflection, on the very process of composing within zones of tension (De Groot, 2020). On a meta-level, education therefore is considered to be a complex concern within Delta Studies. It is object of study itself. Students and lecturers are repositioned towards one another in a composition — and this process requires that particpants stay with trouble, explore the zones of tension, and adapt their pedagogies (hence: provisional pedagogies) on the go.

In more traditional higher education settings, research and education are related but separate activities. They are separated by their actions (what is done) and by the publics that are formed and addressed (who is involved and communicated to). Higher Education workers address and are assessed by students in an education context and address and are judged by peers within research environments. Teachers are experts that transfer knowledge and skills. During their trajectory through Higher Education, students get more and more involved in (scientific or artistic) research as they increasingly master the skills of their expert teachers. Education and research are, in other words, based on the 'master-apprentice' relationship.

Within Delta Studies, the relationship between student and teacher can be described as co-researchers and, on a meta-level, this relationship is in itself subject of research. In this manner, research and education are not only intertwined, but also co-constitutive of each other. In this 'education as research'-model, students and lecturers set out from a concern within the environment of the former (so the issue is not given by the latter), a concern the student wants to be able to respond to. This repositions the student-lecturer relationship, since the expertise of the lecturer is necessary (in terms of process), but, in all likelihood, not sufficient (in terms of content). So, the teacher becomes a participant, too, in the research. Then, the mapping of entanglements results in a need to mobilise, and collaborate with, other forms of knowledges, skills, expertise, and imaginations. This repositions the student away from individual response-ability towards collective response-ability, in a transformative composition. Education becomes research in reciprocity. In this manner, response-ability implies the shift in education from the individual and the matter of fact (to be transferred from lecturer to student) to teamwork and matter of concern (to be discovered by co-researchers). ${ }^{2}$ Education is not the place where knowledge is transferred, it is the place where 'what if'-questions are formulated, knowledges are created, and response-ability is composed.

\section{DELTA STUDIES REIMAGINES MAKING PUBLIC(S)}

Delta Studies reimagines making publics by avoiding extractive approaches to research, teaching and learning. By composing inclusive and equitable processes, Delta Studies does not draw a line between academics, artists and their publics. It does not identify publics as 'stakeholders', but as participants with relevant situated knowledges, skills, and expertise that can contribute to 'composing' (Latour, 2010) and 'composting' (Haraway, 2016) transformative compositions.

Delta Studies reimagines making public, too. Its transformative compositions can be valorised in as many ways as there are situations (and situation- specific needs, possibilities and limitations); its 'output' can have many different manifestations (practico-material, sensorial, aesthetic, scientific, etc.) and forms (interventions, contributions, publications, performances, gatherings, etc.) - as long as making public makes publics, responseability, and $\Delta$.

\footnotetext{
2 This evidently results in forms of assessment that move away from individual assessment (but this is a topic for another article).
} 


\section{REFERENCES}

Barad, K. (2007). Meeting the Universe Halfway: Quantum Physics and the Entanglement of Matter and Meaning. Durham: Duke University Press. https://doi.org/10.2307/j.ctv12101zq

Barad, K. (2010). Quantum Entanglements and Hauntological Relations of Inheritance: Dis/Continuities, SpaceTime Enfoldings, and Justice-to-Come. Derrida Today, 3(2), 240-268. https://doi.org/10.3366/ drt.2010.0206

Barad, K. (2015). On Touching-The Inhuman That Therefore I Am (V.1.1), in S. Witzgall and K. Stakemeier (eds.), Power of the Material/ Politics of Materiality (pp. 153-164). Zurich: Diaphanes eTexT.

Beck, U. (1992). Risk Society: Towards a New Modernity. London/Newbury Park/New Delhi: Sage Publications.

Blaise, M., Hamm, C. and Iorio, J.-M. (2017). Modest witness(ing) and lively stories: paying attention to matters of concern in early childhood. Pedagogy, Culture \& Society, 25(1), 31-42. https://doi.org/10.1080/ 14681366.2016.1208265

Bozalek, V. and Zembylas, M. (2017). Towards a Response-able Pedagogy Across Higher Education Institutions in Post-Apartheid South Africa: An Ethico-Political Analysis. Education as Change, 21(2), 62-85. https://doi.org/10.17159/1947-9417/2017/2017

Bryant, L. (2013). Latour's Principle of Irreduction. Larval Subjects (05/15/2015). Available at: https://larvalsubjects.wordpress.com/2013/05/15/latours-principle-of-irreduction/

Despret, V. (2004). The Body We Care for: Figures of Anthropo-zoo-genesis. Body and Society, 10(2-3), 111-134. https://doi.org/10.1177/1357034X04042938

Despret, V. (2016). What Would Animals Say if We Asked the Right Questions. Minneapolis: University of Minnesota Press. https://doi.org/10.5749/minnesota/9780816692378.001.0001

Eldred, S. (2016). Art-Science Collaborations: Change of Perspective. Nature, 537, 125-126. https://doi.org/10.1038/nj7618-125a

Frietas, E. de (2016). Diffractive Apparatus: Rethinking the Design Experiment in Light of Quantum Ontology. Paper presented at the American Educational Research Association, Washington, DC, April.

Groot, T. de (2020). Transdisciplinary Education Across and Beyond Arts and Sciences: Provisional Pedagogies in Zones of Tension. RASL Transdisciplinary Research. Available at: https://transdisciplinaryresearch.rasl.nu/ $\mathrm{tag} /$ provisional-pedagogies/

Haraway, D. (1992). The Promises of Monsters: A Regenerative Politics for Inapproporiate/d Others, in L. Grossberg, C. Nelson and P. A. Treichler (eds.), Cultural Studies (pp. 295-337). New York: Routledge.

Haraway, D. (1997).Modest_Witness@Second_Millenium: FemaleMan_Meets_OncoMouse: Feminism and Technoscience. New York: Routledge.

Haraway, D. (2016). Staying with the Trouble: Making Kin in the Chthulucene. Durham: Duke University Press. https://doi.org/10.2307/j.ctv11cw25q

Latour, B. (1993). The Pasteurization of France. Cambridge, MA: Harvard University Press.

Latour, B. (2004). Why Has Critique Run out of Steam? From Matters of Fact to Matters of Concern. Critical Inquiry, 30(Winter 2004), 225-248. https:// doi.org/10.1086/421123

Latour, B. (2010). An Attempt at a "Compositionist Manifesto". New Literary History, 41, 471-490.

Latour. B. and Woolgar, S. (1986). Laboratory Life: The Construction of Scientific Facts. Princeton: Princeton University Press. https:// doi.org/10.1515/9781400820412

Morton, T. (2013). Hyperobjects. Philosophy and Ecology after the End of the World. University of Minnesota Press.

Tsing, A. (2000). The Global Situation. Cultural Anthropology, 15(3), 327-360. https://doi.org/10.1525/ can.2000.15.3.327

Vermeulen, T. and Van den Akker, R. (2010). Notes on Metamodernism. Journal of Aesthetics \& Culture, 2(1), 5677. https://doi.org/10.3402/jac.v2i0.5677

Vermeulen, T. and Van den Akker, R. (2015). Utopia, Sort of: A Case Study in Metamodernism. Studia Neophilologica, 87(sup1), 55-67. https://doi.org/10.1080/00393274.2014.981964 